\title{
VARIANTES GEOGRÁFICAS DA LIBRAS: ANÁLISE DOS SINAIS PARA MESES EM GOIÁS E MATO GROSSO DO SUL
}

\author{
GEOGRAPHIC VARIANTS OF LIBRAS: ANALYSIS OF THE SIGNS FOR MONTHS IN \\ THE BRAZILIAN STATES OF GOIÁS AND MATO GROSSO DO SUL
}

\section{VARIACIONES GEOGRÁFICAS DE LIBRAS: ANÁLISIS DE LOS SIGNOS PARA LOS MESES EN GOIÁS Y MATO GROSSO DO SUL}

Fabiane Ferreira da Silva Moraes*

\begin{abstract}
Resumo
O presente trabalho objetiva analisar as variantes geográficas da Libras (Língua Brasileira de Sinais) no que se refere aos sinais utilizados em Goiás e Mato Grosso do Sul, para designar os meses de janeiro a dezembro. A pesquisa, de caráter documental, investigou os sinais listados nos documentos publicados pelo Centro de Capacitação de Profissionais da Educação e de Atendimento às Pessoas com Surdez (CAS). A análise dos dados baseou-se teoricamente na Sociolinguística Variacionista e nos pressupostos fornecidos pelos estudos linguísticos da Libras. Os sinais coletados foram descritos com base nos parâmetros e ordem da Escrita de Línguas de Sinais (ELiS). O estudo do corpus permitiu a identificação de vinte e um sinais distintos, com variação em um, dois ou em todos os parâmetros.
\end{abstract}

Palavras-chave: Libras. Variantes geográficas. Sociolinguística.

\section{Introdução}

A variação linguística, tema amplamente estudado nas línguas orais, também se faz presente nas línguas de sinais. Fatores históricos, sociais, geográficos, entre outros, influenciam o modo como os utentes da Língua Brasileira de Sinais (Libras) constroem e selecionam os itens lexicais utilizados nos processos de comunicação. Dentro dessa ótica, Quadros e Karnopp (2004, p. 33) chamam a atenção para o fato de que "as línguas de sinais são distintas e que há dialetos em tais línguas como os há nas línguas orais”. De acordo com as autoras, a análise dos dicionários das línguas de sinais demonstra que sujeitos surdos utilizam diferentes sinais para se referir a um mesmo termo. A existência de sinais distintos, porém, com o mesmo significado, pode ser facilmente identificada nas enunciações dos membros da comunidade surda de diferentes regiões do Brasil. Ademais,

\footnotetext{
* Mestre em Linguística pela Universidade Federal da Grande Dourados. Bacharel em Teologia pela Faculdade Teológica Batista Ana Wollerman. Professora de Libras e Linguística na Faculdade de Letras da Universidade Federal de Goiás. E-mail: 1librasfabiane@gmail.com
} 
a comparação dos materiais de ensino de Libras, disponibilizados por duas entidades ligadas ao trabalho de Educação e Atendimento a pessoas surdas, evidencia a presença da variação geográfica em inúmeros itens lexicais.

Foram utilizados neste trabalho, como exemplo, os diferentes sinais empregados para designar os meses de janeiro a dezembro, que constam nas apostilas do Centro de Capacitação de Profissionais da Educação e de Atendimento às Pessoas com Surdez de Mato Grosso do Sul (CAS/MS) e do Centro de Capacitação de Profissionais da Educação e de Atendimento às Pessoas com Surdez de Goiás (CAS/GO). Chama a atenção o fato de que, enquanto na Língua Portuguesa a variação dos nomes dos meses se resume a fonética, não havendo distinção morfológica, na Libras, os sinais podem apresentar variação em um número maior de parâmetros.

Neste trabalho, que faz parte de um projeto de pesquisa acerca das variantes geográficas da Libras, apresentamos a descrição e a análise do léxico para meses que consta no material disponibilizado pelo CAS de Goiás e Mato Grosso do Sul. Vale lembrar que, embora o intuito do projeto seja compreender a variação no âmbito nacional, no presente artigo optamos por nos deter aos sinais utilizados nos dois estados citados anteriormente, haja vista a necessidade de delimitação do corpus de pesquisa.

Mesmo que diferentes obras citem a presença da variação na Libras, ainda existem inúmeros aspectos sobre esta temática a serem perscrutados. Conforme referenciam Souza e Segalla (2009), a maior parte das pesquisas acerca das línguas sinais, incluindo a Libras, objetivaram descrever os elementos linguísticos no sentido de comprovar que elas também são línguas naturais. Por esse motivo, "só recentemente está havendo uma crescente preocupação em resgatar os dados concernentes à emergência e desenvolvimento de línguas sinalizadas dentro de uma metodologia sociolinguística" (SOUZA; SEGALLA 2009, p. 27-28).

Desse modo, a pesquisa aqui empreendida visa contribuir com os estudos sociolinguísticos da Libras, apontando, ainda que de forma incipiente, elementos para a sistematização de sua variação geográfica. Tencionar esta sistematização é relevante, haja vista que "a cada situação de fala em que nos inserimos e da qual participamos, notamos que a língua falada é, a um só tempo, heterogênea e diversificada. E é precisamente essa situação de heterogeneidade que deve ser sistematizada" (TARALLO, 1986, p. 6). Para tanto, na primeira parte do artigo apresentamos os pressupostos teóricos da Sociolinguística Variacionista, os tipos de variação e a caracterização da variação 
geográfica. Em seguida, descrevemos a metodologia de pesquisa e de descrição dos sinais. No tópico que segue são listados os sinais que compõem o corpus e a pormenorização de cada parâmetro das variantes encontradas. Por fim, são discutidos os resultados obtidos a partir da análise.

\section{Pressupostos teóricos}

A pesquisa se inscreve no campo da Sociolinguística Variacionista, corrente teórica que "busca explicar empiricamente como as estruturas internas de uma determinada língua são submetidas às variações desencadeadas por fatores externos no uso linguístico real" (SOUZA, SEGALLA, 2009, p. 24). Uma das premissas fundamentais desse campo de estudo é o reconhecimento da heterogeneidade constitutiva das línguas. Segundo Camacho (2001, p. 55) “a diversidade é uma propriedade funcional e inerente aos sistemas linguísticos". Tal propriedade pode ser observada nas inúmeras variantes encontradas nas línguas, sejam elas orais ou de sinais.

As variantes linguísticas podem ser definidas como as "diversas maneiras de se dizer a mesma coisa em um mesmo contexto, e com o mesmo valor de verdade. A um conjunto de variantes dá-se o nome de variável linguística" (TARALLO, 1986, p. 10). Na Língua Portuguesa é frequente o uso do exemplo dos termos "macaxeira", "mandioca" ou “aipim” para ilustrar o conceito de variante. À luz do conceito de Tarallo podemos afirmar que as variantes linguísticas na Libras equivalem aos sinais diversos que são usados para dizer a mesma coisa. É o que ocorre, por exemplo, com os sinais para o termo "pai", registrados na apostila do CAS/MS:

Imagem 1: Variantes para "pai"

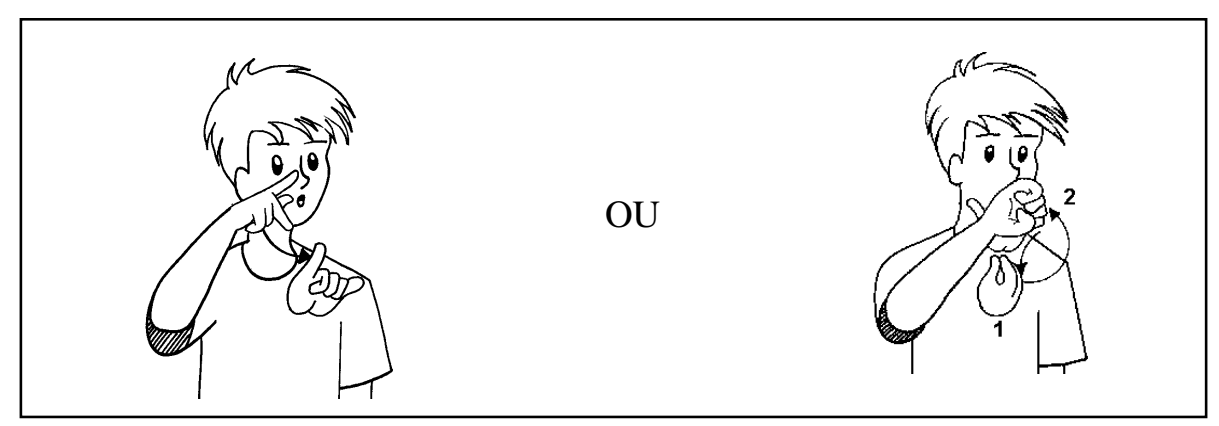

Fonte: CAS/MS

Faz-se necessário ressaltar os diferentes tipos de variação listados por Cezário e Votre (2011, p. 144-145), a saber: a variação geográfica (ou regional), a social e a de 
registro. A primeira diz respeito aos diferentes modos de enunciação em espaços geográficos distintos, como nos estados do Rio Grande do Sul e São Paulo, por exemplo. A variação social refere-se aos modos de enunciar de grupos sociais de uma mesma região, ela envolve a análise por faixa etária, poder aquisitivo, escolaridade, gênero entre outros. Já a variação de registro vincula-se ao meio de comunicação, como o modo de enunciar em uma carta, em uma conversa informal ou em um bilhete.

Em geral, os fatores sociais, geográficos e de registro, não se apresentam de forma isolada, antes, há uma correlação entre eles. Acerca dessa relação, Cezario e Votre (2011, p. 145) afirmam que a inovação linguística pode ter início em uma "determinada região (variável regional), mas é própria de um grupo socioeconômico desfavorecido (variável social) [...] pode passar a ser usada pelo grupo socioeconômico mais alto nos momentos mais informais (a variável é, então, o registro)". Mesmo considerando a indissociabilidade dos fatores citados anteriormente, no presente trabalho o objeto de estudo são as variantes regionais (ou geográficas) da Libras. Camacho (2001) salienta que a variação geográfica pode ser facilmente percebida nas diversas formas de enunciação no Brasil. De acordo com o Camacho (2001, p.58), assim como,

[...] é verdadeiro que o domínio de uma língua deriva do grau de contato do falante com outros membros da comunidade, também é verdadeiro que quanto maior o intercâmbio entre os falantes de uma língua, tanto maior a semelhança entre seus atos verbais. Dessa tendência para maior semelhança entre os atos verbais dos membros de uma mesma comunidade resulta a variação geográfica.

Tal variação também pode ser percebida na língua de sinais. Strobel e Fernandes (2008, p. 3) descrevem os sinais que são empregados em diferentes regiões do Brasil para expressar um mesmo sentido e citam como exemplo os sinais para "verde" e "mas", utilizados em São Paulo, Rio de Janeiro e Curitiba. Apresentamos a seguir a metodologia utilizada para descrição e análise de alguns atos verbais da comunidade surda goiana e atos verbais da comunidade surda sul-mato-grossense para expressar os meses do ano.

\section{Metodologia}

A pesquisa, de caráter documental, tem como corpus os documentos publicados e disponibilizados na internet pelos CAS de Goiás e Mato Grosso do Sul. Para a descrição dos sinais, optamos pelos parâmetros e ordem da Escrita de Línguas de Sinais (ELiS), propostos por Barros (2007, 2015). São eles: configurações de dedo (CD), orientação da palma (OP), ponto de articulação (PA) e movimento (M). Por se tratar de uma pesquisa 
documental, as expressões não-manuais não foram investigadas. A análise dos dados baseou-se nas contribuições teóricas e metodológicas da Sociolinguística Variacionista em interface com os estudos acerca da linguística da Libras.

A análise dos sinais seguiu a ordem dos meses no calendário anual. Primeiramente, listamos os sinais que constam no material disponibilizado pelo CAS/GO e pelo CAS/MS. Considerando-se que na apostila do CAS/GO os sinais são mostrados através da fotografia de um sinalizador, optamos por não utilizar a imagem original e proceder a uma reprodução da mesma. Na apostila do CAS/MS os sinais são representados por desenhos e, visando a padronização da apresentação dos sinais no presente trabalho, optamos por reproduzi-los por meio de fotografias.

As imagens que descrevem os sinais para cada mês são seguidas da análise detalhada dos parâmetros que compõem as variantes. Descrevemos a configuração de dedos, orientação da palma, ponto de articulação e movimento. Especificamos também, de acordo com Barros (2015 p. 82-84), se o sinal é monomanual (realizado com uma única mão), bimanual simétrico (com as duas mãos e todos os parâmetros iguais), bimanual assimétrico (com as duas mãos, mas com os parâmetros diferentes) ou composto (formado pela justaposição de dois ou mais sinais). Para a descrição dos sinais compostos indicamos o numeral 1 para o primeiro sinal e o numeral 2 para o segundo sinal.

\section{Parâmetros e Variantes de cada um dos meses}

$\mathrm{Na}$ sinalização de "Janeiro" foram identificados dois sinais diferentes. Note-se o empréstimo linguístico nos dois sinais e o fato de que a variante sul-mato-grossense é formada por um sinal composto, conforme pode ser observado na Figura 2 e no Quadro 1:

Figura 2. Mês de Janeiro

Mão direita em "J" horizontal, palma para baixo.
Balançar a mão para a direita e para a esquerda
duas vezes.


Quadro 1. Parâmetros e variantes do mês de Janeiro

\begin{tabular}{|l|l|l|}
\hline Parâmetro & Variante Goiás & Variante Mato Grosso do Sul \\
\hline CD & $\begin{array}{l}\text { Polegar, indicador, médio e e } \\
\text { anelar fechados; mínimo } \\
\text { estendido }\end{array}$ & $\begin{array}{l}\text { 1. Polegar, indicador, médio e anelar fechados; } \\
\text { mínimo estendido } \\
\text { 2. Polegar fechado; indicador estendido; } \\
\text { demais dedos fechados }\end{array}$ \\
\hline OP & Palma para frente & $\begin{array}{l}\text { 1. Palma para frente } \\
\text { 2. Palma para frente }\end{array}$ \\
\hline PA & Espaço neutro & $\begin{array}{l}\text { 1. Espaço neutro } \\
\text { 2. Ao lado do corpo }\end{array}$ \\
\hline MOV & Girar o antebraço & $\begin{array}{l}\text { 1. Girar o antebraço } \\
\text { 2. Flexionar os dedos na primeira articulação }\end{array}$ \\
\hline Tipo do sinal & Sinal monomanual & Sinal composto \\
\hline
\end{tabular}

Observa-se, na Figura 3 e no Quadro 2, o registro de três sinais para o mês de fevereiro: um divulgado no material do CAS/GO e dois sinas (duas variantes) no material do CAS/MS:

Figura 3. Mês de Fevereiro

\begin{tabular}{|l|l|l|}
\hline Goiás & Mato Grosso do Sul \\
\hline $\begin{array}{l}\text { Mão direita em "F" vertical, } \\
\text { balançando para direita e } \\
\text { esquerda. }\end{array}$ & Variante 2a & Variante $2 \mathrm{~b}$ \\
\hline
\end{tabular}

Quadro 2. Parâmetros e variantes do mês de Fevereiro

\begin{tabular}{|l|l|l|l|}
\hline Parâmetro & \multicolumn{1}{|c|}{ Variante 1 - GO } & \multicolumn{1}{|c|}{ Variante 2a - MS } & \multicolumn{1}{|c|}{ Variante 2b - MS } \\
\hline CD & $\begin{array}{l}\text { Polegar na vertical; } \\
\text { Indicador inclinado; demais } \\
\text { dedos estendidos }\end{array}$ & $\begin{array}{l}\text { Polegar na vertical; } \\
\text { demais dedos } \\
\text { estendidos }\end{array}$ & $\begin{array}{l}\text { Polegar fechado; } \\
\text { Indicador édio } \\
\text { estendidos; demais } \\
\text { dedos fechados }\end{array}$ \\
\hline OP & Palma para frente & Palma para trás & Palma para frente \\
\hline PA & Lateral do corpo & $\begin{array}{l}\text { Espaço à frente do } \\
\text { rosto }\end{array}$ & Lateral do corpo \\
\hline MOV & $\begin{array}{l}\text { Do braço para a esquerda e } \\
\text { direita }\end{array}$ & Girar o antebraço & $\begin{array}{l}\text { Do braço: para cima e } \\
\text { para baixo }\end{array}$ \\
\hline $\begin{array}{l}\text { Tipo do } \\
\text { sinal }\end{array}$ & Sinal monomanual & Sinal monomanual & $\begin{array}{l}\text { Sinal bimanual } \\
\text { simétrico }\end{array}$ \\
\hline
\end{tabular}


O mês de Março, no material do CAS/GO, é indicado através da datilologia, enquanto no material do CAS/MS é feita a soletração rítmica, como apresentado na Figura 4 e no Quadro 3:

Figura 4. Mês de Março

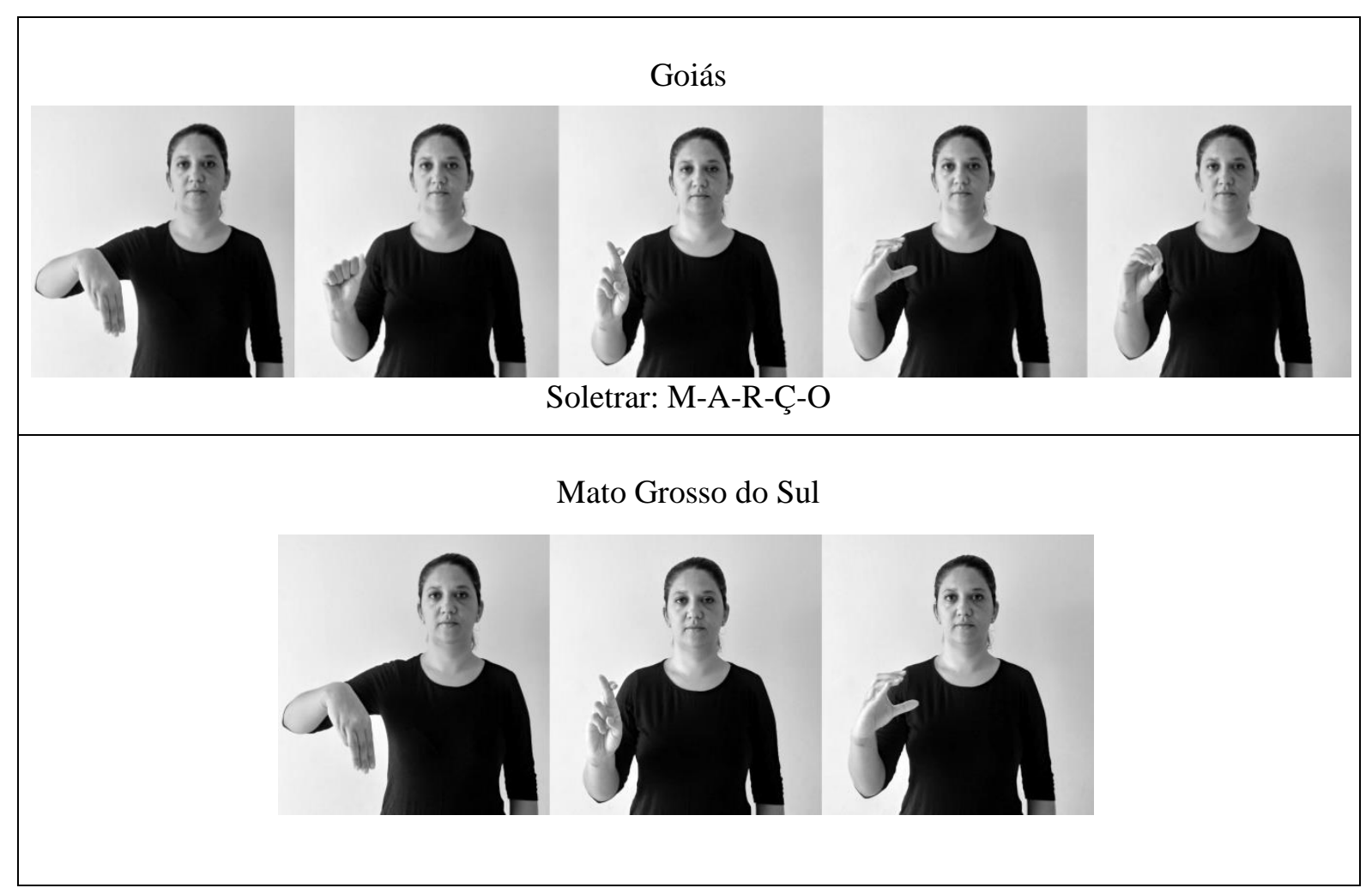

Quadro 3. Parâmetros e variantes do mês de Março

\begin{tabular}{|l|l|l|}
\hline \multirow{3}{*}{ Parâmetro } & Variante 1 - GO & Variante 2 - MS \\
\cline { 2 - 3 } & Soletração de MARÇO & Soletração das letras M-R-Ç \\
\hline Tipo do sinal & Sinal soletrado & Soletração rítmica \\
\hline
\end{tabular}

O sinal utilizado para designar o mês de Abril é o mesmo em Goiás e no Mato Grosso do Sul, conforme pode ser observado na Figura 5 e no Quadro 4: 
Figura 5. Mês de Abril

Mão direita em "A" vertical, próximo ao lado
direito do pescoço. Mover a mão para cima e
para direita.

Quadro 4. Parâmetros e variantes do mês de Abril

\begin{tabular}{|l|l|l|}
\hline Parâmetro & Variante Goiás & Variante Mato Grosso do Sul \\
\hline CD & $\begin{array}{l}\text { Polegar na vertical; demais dedos } \\
\text { fechados }\end{array}$ & $\begin{array}{l}\text { Polegar na vertical; demais dedos } \\
\text { fechados }\end{array}$ \\
\hline OP & Palma para frente & Palma para frente \\
\hline PA & Pescoço & Pescoço \\
\hline MOV & Para cima e para a direita & Para cima e para a direita \\
\hline Tipo do sinal & Sinal monomanual & Sinal monomanual \\
\hline
\end{tabular}

$\mathrm{Na}$ variante goiana para o mês de Maio, é usada a datilologia, enquanto no Mato Grosso do Sul o sinal é o que se pode observar na Figura 6 e no Quadro 5:

Figura 6. Mês de Maio

Soletrar: M-A-I-O

Revista Sinalizar, Goiânia, v. 3, n.2, p.39-55, jul. / dez., 2018. 
Mato Grosso do Sul

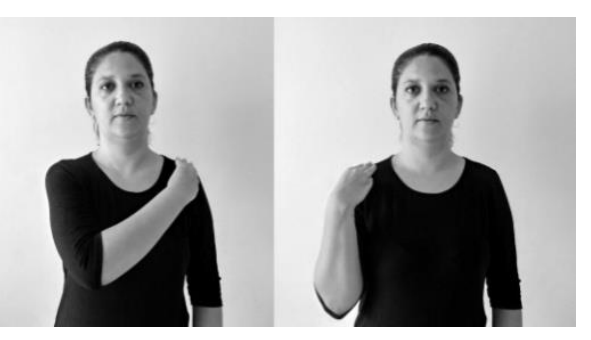

Quadro 5. Parâmetros e variantes do mês de Maio

\begin{tabular}{|l|l|l|}
\hline Parâmetro & Variante Goiás & Variante Mato Grosso do Sul \\
\hline CD & Soletrar MAIO & $\begin{array}{l}\text { Polegar fechado; indicador, médio e } \\
\text { anelar estendido; mínimo fechado }\end{array}$ \\
\hline OP & & Palma para baixo \\
\hline PA & & Ombros \\
\hline MOV & & Do braço: arco \\
\hline Tipo do sinal & Sinal soletrado & Sinal monomanual \\
\hline
\end{tabular}

Assim como acontece com o mês de Abril, o sinal para Junho também é idêntico em Goiás e Mato Grosso do Sul:

Figura 7. Mês de Junho

\begin{tabular}{|l|l|}
\hline Goiás \\
\hline $\begin{array}{l}\text { Mãos em "U" horizontal, palmas para baixo, } \\
\text { movê-las para cima e para baixo, batendo os } \\
\text { dedos uns contra os outros. }\end{array}$
\end{tabular}

Quadro 6. Parâmetros e variantes do mês de Junho

\begin{tabular}{|l|l|l|}
\hline Parâmetro & Variante Goiás & Variante Mato Grosso do Sul \\
\hline CD & $\begin{array}{l}\text { Polegar fechado; indicador e médio } \\
\text { estendidos; demais dedos fechados }\end{array}$ & $\begin{array}{l}\text { Polegar fechado; indicador e médio } \\
\text { estendidos; demais dedos fechados }\end{array}$ \\
\hline OP & Palma para baixo & Palma para baixo \\
\hline PA & Dedos & Dedos \\
\hline MOV & Do braço: para cima e para baixo & Do braço: para cima e para baixo \\
\hline Tipo do sinal & Sinal bimanual simétrico & Sinal bimanual simétrico \\
\hline
\end{tabular}


De forma semelhante ao que ocorre com os sinais para o mês de Março, em Goiás o mês de Julho é representado pela datilologia e em Mato Grosso do Sul, pela soletração rítmica das letras J-L:

Figura 8. Mês de Julho

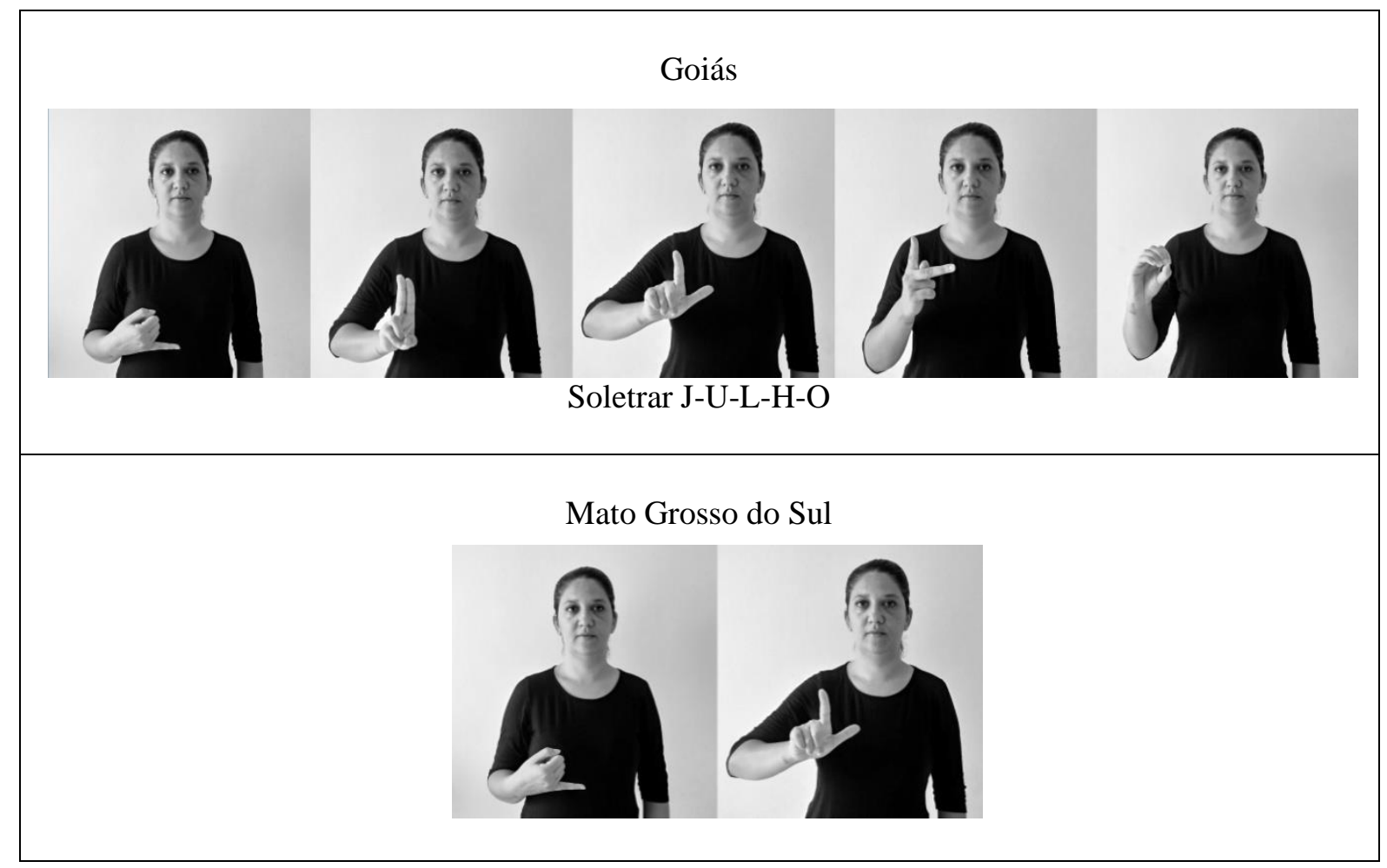

Quadro 7. Parâmetros e Variantes

\begin{tabular}{|l|l|l|}
\hline Parâmetro & Variante Goiás & $\begin{array}{l}\text { Variante Mato Grosso do } \\
\text { Sul }\end{array}$ \\
\hline & Soletrar JULHO & Soletrar J-L \\
\hline Tipo do sinal & Sinal soletrado & Soletração rítmica \\
\hline
\end{tabular}

É possível observar, na Figura 9 e no Quadro 8, a semelhança dos sinais usados em Goiás e Mato Grosso do Sul para indicar o mês de Agosto. A distinção entre esses sinais ocorre na ordem de sinalização e também no movimento. 
Figura 9. Mês de Agosto

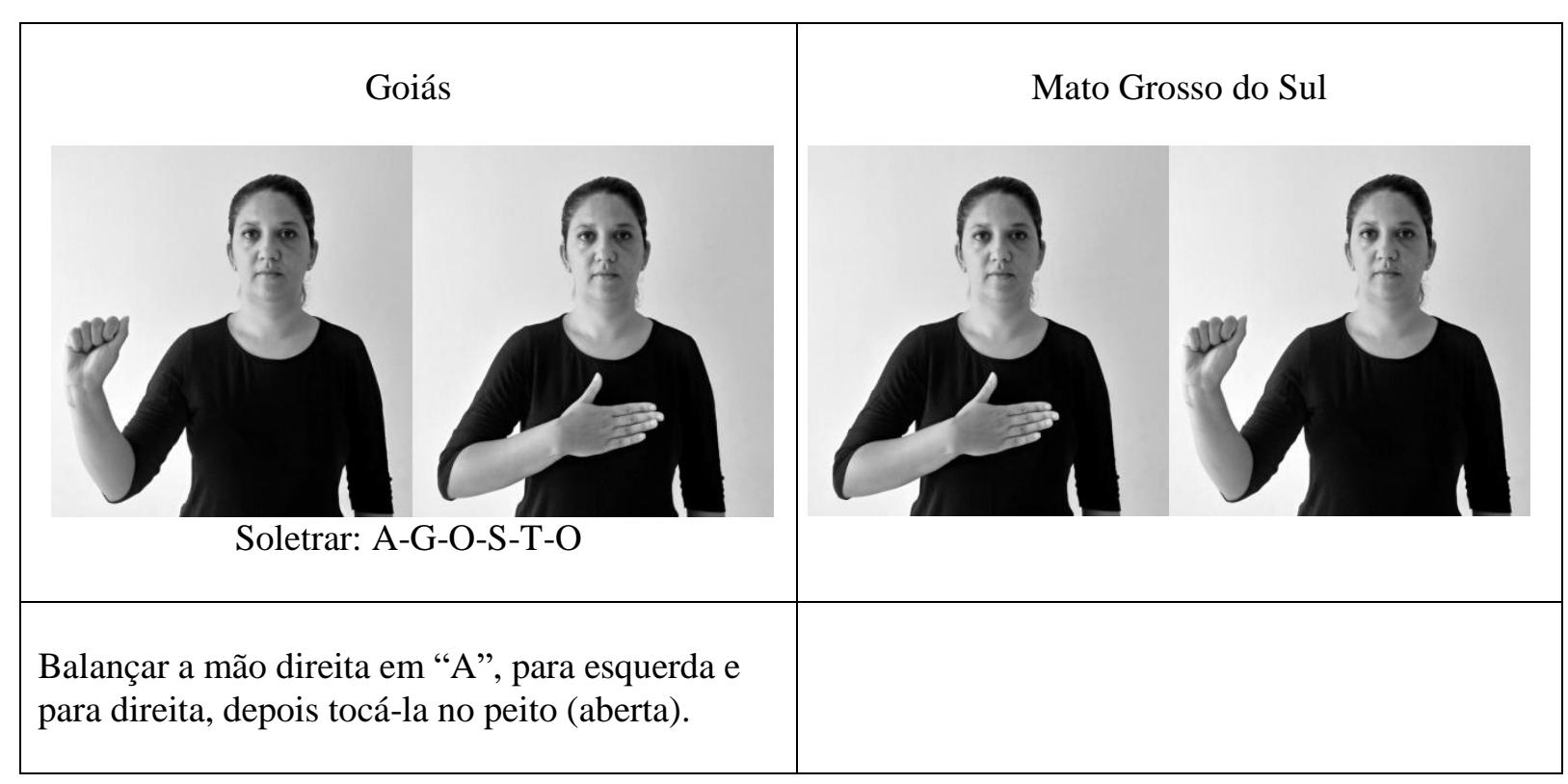

Quadro 8. Parâmetros e Variantes do mês de Agosto

\begin{tabular}{|l|l|l|}
\hline Parâmetro & Variante Goiás & Variante Mato Grosso do Sul \\
\hline CD & $\begin{array}{l}\text { 1. Polegar na vertical; demais dedos } \\
\text { fechados } \\
\text { 2. Polegar na horizontal; demais dedos } \\
\text { estendidos }\end{array}$ & $\begin{array}{l}\text { 1. Polegar na horizontal; demais } \\
\text { dedos estendidos } \\
\text { 2. Polegar na vertical; demais dedos } \\
\text { fechados }\end{array}$ \\
\hline OP & $\begin{array}{l}\text { 1. Palma para frente } \\
\text { 2. Palma para trás }\end{array}$ & $\begin{array}{l}\text { 1. Palma para trás } \\
\text { 2. Palma para frente }\end{array}$ \\
\hline PA & $\begin{array}{l}\text { 1. Ao lado do corpo } \\
\text { 2. Tórax }\end{array}$ & $\begin{array}{l}\text { 1. Tórax } \\
\text { 2. Ao lado do corpo }\end{array}$ \\
\hline MOV & $\begin{array}{l}\text { 1. Do braço: para a direita e para a a } \\
\text { 2. Do braço: para trás }\end{array}$ & $\begin{array}{l}\text { 1. Do braço: para baixo } \\
\text { 2. Do braço: para cima e para a } \\
\text { direita }\end{array}$ \\
\hline Tipo do sinal & Sinal composto & Sinal composto \\
\hline
\end{tabular}

No sinal para o mês de Setembro, apenas uma distinção é percebida: a configuração de dedos. Como se pode observar na Figura 10 e no Quadro 9, enquanto na variante goiana o polegar está na palma, na variante de Mato Grosso do Sul o polegar está na horizontal. 
Figura10. Mês de Setembro

\begin{tabular}{|l|l|}
\hline Goiás \\
\hline $\begin{array}{l}\text { Mãos paralelas dedos unidos, e mãos em forma } \\
\text { de concha, palmas para baixo. Levar os dedos } \\
\text { para frente e para trás. }\end{array}$
\end{tabular}

Quadro 9. Parâmetros e variantes do mês de Setembro.

\begin{tabular}{|l|l|l|}
\hline Parâmetro & Variante Goiás & Variante Mato Grosso do Sul \\
\hline CD & $\begin{array}{l}\text { Polegar na palma; demais dedos } \\
\text { inclinados }\end{array}$ & $\begin{array}{l}\text { Polegar na horizontal; demais dedos } \\
\text { inclinados }\end{array}$ \\
\hline OP & Palma para baixo & Palma para baixo \\
\hline PA & Ao lado do corpo & Ao lado do corpo \\
\hline MOV & Mover o punho lateralmente & Mover o punho lateralmente \\
\hline Tipo do sinal & Sinal bimanual simétrico & Sinal bimanual simétrico \\
\hline
\end{tabular}

Como exposto na Figura 11 e no Quadro 10, o sinal para o mês de Outubro é idêntico nos dois estados, assim como ocorre com o sinal para o mês de Junho,.

Figura 11. Mês de Outubro

\begin{tabular}{|l|l|}
\hline Goiás & Mato Grosso do Sul \\
\hline $\begin{array}{l}\text { Mão direita em "O", fazendo movimento } \\
\text { circular no sentido horário. }\end{array}$
\end{tabular}


Quadro 10. Parâmetros e variantes do mês de Outubro

\begin{tabular}{|l|l|l|}
\hline Parâmetro & Variante Goiás & Variante Mato Grosso do Sul \\
\hline CD & $\begin{array}{l}\text { Polegar curvo; demais dedos curvos em } \\
\text { contato com o polegar }\end{array}$ & $\begin{array}{l}\text { Polegar curvo; demais dedos curvos em } \\
\text { contato com o polegar }\end{array}$ \\
\hline OP & Palma para frente & Palma para frente \\
\hline PA & Ao lado do corpo & Ao lado do corpo \\
\hline MOV & Circular frontal & Circular frontal \\
\hline Tipo do sinal & Sinal monomanual & Sinal monomanual \\
\hline
\end{tabular}

O sinal para o mês de Novembro é monomanual em Goiás e composto em Mato Grosso do Sul, como pode ser observado na Figura 12 e no Quadro 11.

Figura 12. Mês de Novembro

\begin{tabular}{l} 
Goiás \\
\hline A mão direita em "N" é movida, \\
ligeiramente, para cima e para baixo.
\end{tabular}

Quadro 11. Parâmetros e variantes do mês de Novembro

\begin{tabular}{|l|l|l|}
\hline Parâmetro & Variante Goiás & Variante Mato Grosso do Sul \\
\hline CD & $\begin{array}{l}\text { Polegar fechado; indicador e médio } \\
\text { estendidos; anelar e mínimo fechado }\end{array}$ & $\begin{array}{l}\text { Polegar fechado; indicador e } \\
\text { médio estendidos; anelar e } \\
\text { mínimo fechado }\end{array}$ \\
\hline OP & Palma para trás & $\begin{array}{l}\text { Palma para baixo em seguida } \\
\text { palma para trás }\end{array}$ \\
\hline PA & Ao lado do corpo & $\begin{array}{l}\text { Pescoço e em seguida ao lado do } \\
\text { corpo }\end{array}$ \\
\hline MOV & Do braço: para cima e para baixo & $\begin{array}{l}\text { Do braço para a direita e em } \\
\text { seguida do braço para cima e } \\
\text { para baixo }\end{array}$ \\
\hline Tipo do sinal & Sinal monomanual & Sinal monomanual \\
\hline
\end{tabular}


O sinal para o mês de Dezembro é igual em Goiás e em Mato Grosso do Sul, como é possível observar na Figura 13 e no Quadro 12.

Figura 13. Mês de Dezembro

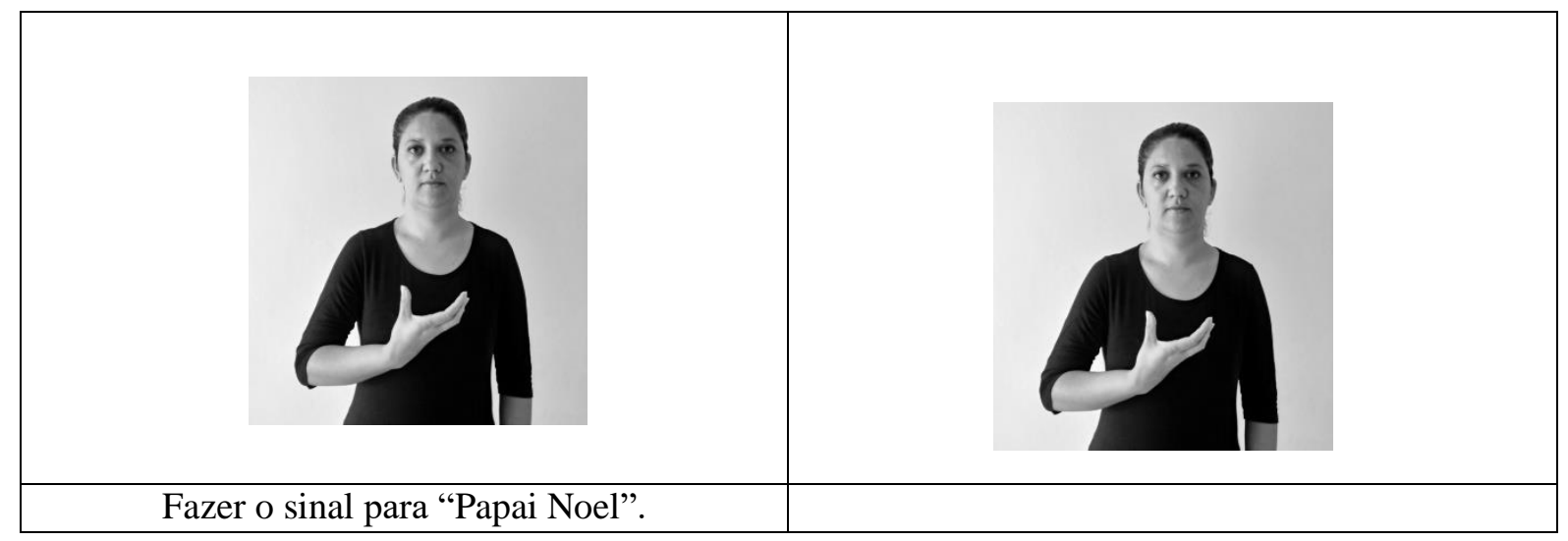

Quadro 12. Parâmetros e variantes do mês de Dezembro

\begin{tabular}{|l|l|l|}
\hline Parâmetro & Variante Goiás & Variante Mato Grosso do Sul \\
\hline CD & $\begin{array}{l}\text { Polegar na horizontal; demais dedos } \\
\text { curvos }\end{array}$ & $\begin{array}{l}\text { Polegar na horizontal; demais dedos } \\
\text { curvos }\end{array}$ \\
\hline OP & Palma para cima & Palma para cima \\
\hline PA & Espaço neutro & Espaço neutro \\
\hline MOV & Do braço: para cima e para baixo & Do braço: para cima e para baixo \\
\hline Tipo do sinal & Sinal monomanual & Sinal monomanual \\
\hline
\end{tabular}

\section{Resultados}

A comparação entre as publicações do CAS/GO e do CAS/MS permitiu a catalogação de vinte e um sinais distintos para representar os meses de janeiro a dezembro. Dentre os sinais analisados, apenas os que se referem aos meses de Abril, Junho, Outubro e Dezembro são pariformes nos dois estados. Os sinais para os demais meses (oito sinais, ou seja, $2 / 3$ do léxico analisado) apresentam distinção em um ou mais parâmetros.

Outro aspecto observado é a frequência do empréstimo linguístico na constituição dos sinais investigados. Nota-se que dos doze sinais listados na apostila do CAS/GO, 3/4 contêm o empréstimo linguístico, apenas os meses de Junho, Setembro e Dezembro fogem desta regra. a designação para Março, Maio e Julho é realizada através da datilologia, ou seja, um quarto do léxico dos meses é representado dessa forma. 
Por outro lado, dos sinais apresentados na apostila do CAS/MS oito contêm o empréstimo linguístico e nenhum é realizado pela datilologia do nome completo. Nos meses de Março e Julho temos a soletração de algumas letras, como MRÇ e JL. Tal observação levou-nos a indagação se o uso da datilologia e dos empréstimos é mais frequente em Goiás do que em Mato Grosso do Sul. A resposta para esse questionamento exige uma pesquisa quantitativa que abranja outros itens lexicais. Pretende-se realizar tal pesquisa no decorrer do projeto em que este artigo se inscreve.

Acrescente-se o fato de que na apostila do CAS/GO há uma breve descrição do sinal abaixo de cada imagem, por exemplo, para o sinal de junho "Mãos em U horizontal, palmas para baixo, movê-las para cima e para baixo, batendo os dedos uns contra os outros". Já na apostila do CAS/MS a indicação dos movimentos é realizada através de setas inseridas no desenho. Cabe destacar que no início da apostila elaborada no MS há uma descrição de cada seta para indicar o movimento e como ele deve ser realizado.

Convêm sublinhar que a única variação registrada nos materiais é a que se refere ao mês de fevereiro, listada na apostila do CAS/MS. Ainda que as variantes não sejam listadas nos materiais que fazem parte do corpus de pesquisa, o contato com as comunidades surdas dos dois estados evidencia a existência de outros sinais para indicar, por exemplo, o mês de julho, em Goiás. Tal situação leva-nos a questionar os motivos pelos quais optou-se por uma variação para compor as apostilas, em detrimento das outras.

\section{Considerações finais}

Durante o desenvolvimento do trabalho aqui apresentado, procuramos deslindar elementos que contribuam para a sistematização das variantes geográficas da Libras. Embora os estudos sejam incipientes, alguns fatores chamaram a atenção. Acreditamos que a observação destes pontos pode contribuir para o estudo das variantes em outros grupos lexicais, bem como, para a análise das variantes em outras unidades federativas. Um dos elementos a ser considerado é a presença dos empréstimos linguísticos e da datilologia na constituição dos sinais. Eles são mais frequentes em algumas comunidades surdas do que em outras? Se sim, por quais motivos?

Em segundo lugar, faz-se necessário refletir sobre a representação dos sinais nas publicações voltadas para o ensino de Libras. Como os materiais têm sido constituídos? Com o uso de imagens, desenhos, escrita de sinais? A descrição é feita com setas, orientações em língua portuguesa? As formas de representação influenciam positiva ou 
negativamente o processo de ensino e aprendizagem da Libras?

Cabe também observar o registro (ou não) das variantes linguísticas no material didático dos Centros de Capacitação de Profissionais da Educação e de Atendimento às Pessoas com Surdez. Quais os critérios para a seleção de uma variante para compor a obra? Por quais motivos as demais variantes não foram registradas? Qual a importância do ensino das variantes para aprendizes de Libras? Ademais, pode-se ponderar sobre a iconicidade e arbitrariedade dos sinais. A iconicidade ou arbitrariedade se faz mais presente em uma região que em outras? Alguns grupos lexicais tendem a apresentar sinais arbitrários mais do que outros grupos?

As indagações listadas anteriormente indicam que as variantes geográficas da Libras constituem um amplo campo de pesquisa. Os questionamentos assinalam também que estudo pormenorizado das variantes pode contribuir com os estudos linguísticos da Libras, bem como com a área de ensino de Libras.

\begin{abstract}
The present work aims to analyze the geographical variants of the Brazilian Sign Language (Libras), specifically with respect to the signs used in Goiás and Mato Grosso do Sul to designate the months of January to December. The research, of a documentary nature, investigated the signs listed in the documents published by the Training Center for Education Professionals and Assistance for Persons with Deafness (CAS). The analysis of the data was based on the theoretical basis of Variationist Sociolinguistics and on the assumptions provided by the linguistic studies of Libras. The collected signals were described based on the parameters and order of Signal Language Writing (ELiS). The verification of the corpus allowed the identification of twenty-one distinct signals, with variation in one, two or all parameters.
\end{abstract}

Keywords: Libras. Geographical variation. Sociolinguistics.

\title{
Resumen
}

Este trabajo tiene lo objetivo de analizar las variaciones geográficas de la Lengua Brasileña de Señales (Libras) específicamente en lo que se refiere a los signos utilizados en Goiás y Mato Grosso do Sul para designar los meses de enero a diciembre. La investigación, de carácter documental, investigó los signos enumerados en los documentos publicados por los Centro de Capacitación de Profesionales de la Educación y de Atención a las Personas con Sordera (CAS). El análisis de los datos se basó teóricamente en la Sociolingüística Variacional y en los supuestos proporcionados por los estudios lingüísticos de Libras. Las señales recogidas se describieron tomando como base los patrones y orden de la Escritura 
de Lenguas de Señales (ELIS). El estudio del corpus permitió la identificación de veintiún signos distintos, con variación en uno, dos o en todos los patrones.

Palabras clave: Libras. Variantes geográficas. Sociolingüística.

\section{Referências}

BARROS, Mariângela Estelita. Escrita das Línguas de Sinais. In: QUADROS, Ronice Müller de; PERLIN, Gladis (org.). Estudos Surdos II. Petrópolis: Arara Azul, 2007.

ELiS: Sistema Brasileiro de Escrita as línguas de sinais. Porto Alegre: Penso, 2015

CAMACHO, Roberto Gomes. Sociolinguística. In: MUSSALIM, F.; BENTES, A. C. (org.). Introdução à Lingüística. v. 1. São Paulo: Contexto, 2001.

CENTRO DE CAPACITAÇÃO DE PROFISSIONAIS DA EDUCAÇÃO E DE ATENDIMENTO ÀS PESSOAS COM SURDEZ/ GOIÁS. Apostila Libras I. Goiás: Secretaria de Educação, 2011.

CEZARIO, Maria Maura; VOTRE, Sebastião. Sociolinguística. In: MARTELOTTA, Mário Eduardo (org.). Manual de linguística. São Paulo: Contexto, 2011.

QUADROS, R. M. de \& KARNOPP, L. Língua de sinais brasileira: estudos lingüísticos. Porto Alegre: ArtMed, 2004.

SEGALA, Rimar Romano; SOUZA, Rosemeri Bernieri. A perspectiva social na emergência das Línguas de Sinais: a noção de "Comunidade de fala" e idioleto segundo o modelo teórico laboviano. In: QUADROS, Ronice Müller de; STUMPF, Marianne Rossi (org.). Estudos Surdos IV. Petrópolis: Arara Azul, 2009.

STROBEL, Karin Lilian; FERNANDES, Sueli. Aspectos lingüísticos da Libras. Curitiba: SEED/SUED/DEE, 2008.

TARALLO, Fernando. A pesquisa sociolingüística. São Paulo: Ática, 1986. 